\title{
HUBUNGAN ANTARA PENGGUNAAN OBAT ATORVASTATIN TERHADAP PERBAIKAN KLINIS PASIEN STROKE ISKEMIK DI RSUP DR. WAHIDIN SUDIROHUSODO
}

\author{
Riska Purnamasari ${ }^{1}$, Marianti A.Manggau ${ }^{1}$, Muhammad Yunus Amran ${ }^{2}$ \\ ${ }^{1}$ Fakultas Farmasi, Universitas Hasanuddin, Makassar \\ ${ }^{2}$ Departemen Neurologi, Fakultas Kedokteran, Universitas Hasanuddin, Makassar
}

\section{Kata Kunci :}

Stroke Iskemik,

Atrovastatin

Kolesterol, GCS, $m R S$

\begin{abstract}
ABSTRAK
Indonesia menduduki terbanyak di Asia yang menderita stroke. Statin dengan efek pleiotropiknya dapat menjadi neuroprotektan sehingga dapat memperbaiki kondisi klinis dan mencegah terjadinya stroke berulang, Di rumah sakit ataupun di klinik ada pasien yang mendapatkan terapi atorvastatin dan ada pula yang tidak. Penelitian ini bertujuan menganalisis efektivitas atorvastatin terhadap pasien stroke iskemik dengan menganaisis nilai kolestrol total, HDL, LDL, dan atorvastatin terhadap perbaikan klinis pasien dengan pengukuran nilai gcs dan $m R S$.Desain penelitian yang digunakan adalah observasional non eksperimen deskriptif-analitik. Pengambilan sampel dengan teknik non-probability sampling dengan cara purposive sampling.Jumlah sampel 30, terdiri dari kelompok atorvastatin (15 pasien) dan kelompok tanpa Atorvastatin (15 pasien). Kolestrol total, HDL, dan LDL, dan $m R S$ diperiksa sebelum dan setelah terapi. Data kolestrol dianalisis secara deskriptif, dan nilai mRS dianalisis dengan menggunakan Uji paried $t$ Test. Hasil penelitian menunjukkan terjadi penurunan nilai kolestrol total (25\%) dengan nilai rata-rata 194.80 dan setelah terapi 151.40 , sedangkan untuk nilai HDL tidak terjadi peningkatan, sebelum terapi (31.00 setelah terapi menjadi 27.00 , dan untuk LDL tidak terjadi penurunan yang signifikan, sebelum terapi $113.80 \mathrm{mg} / \mathrm{dl}$ dan setelah terapi menjadi 93.20, sedangkan untuk perbaikan nilai $m R S$, memberikan hasil mRS yang meningkat secara signifikan dari kelompok atorvastatin $(p=0.001)$ dibandingkan pasien yang tidak diterapi dengan atorvastatin $(p=0.610)$. Dapat disimpulkan bahwa ada hubungan yang signifikan dari pemberian Atorvastatin terhadap perbaikan klinis pasien yang diukur dengan $m R S$ (modified rankin scale)
\end{abstract}

\section{PENDAHULUAN}

Stroke merupakan penyebab kematian ketiga di dunia setelah penyakit jantung koroner dan kanker, baik di negara maju maupun negara berkembang. Satu dari 10 kematian disebabkan oleh stroke (1-3). Secara global, 15 juta orang terserang stroke setiap tahunnya, satu pertiga meninggal dan sisanya mengalami kecacatan permanen (3). Di kawasan Asia tenggara terdapat 4,4 juta orang mengalami stroke (4). Pada tahun 2020 diperkirakan 7,6 juta orang akan meninggal dikarenakan penyakit stroke ini (5). Berdasarkan data yang berhasil dikumpulkan oleh Yayasan Stroke Indonesia (Yastroki), jumlah penderita stroke di Indonesia adalah terbanyak dan menduduki urutan pertama di Asia (6).

Statin telah terbukti mengurangi risiko stroke kira-kira $30 \%$ pada pasien dengan penyakit arteri koroner dan lipid plasma yang tinggi. National Cholesterol Education Programe (NCEP) menganggap stroke iskemik atau TIA (transient ischemia attack) menjadi koroner "Setara" dan telah merekomendasikan penggunaan statin untuk mencapai pengurangan nilai konsentrasi lipoprotein (LDL) kurang dari 100 mg/dl (8).

Beberapa studi menyatakan bahwa statin dengan segera dapat menurunkan kadar lipid sehinga dapat meningkatkan kondisi klinis stroke dan mengurangi resiko terjadinya stroke dikarenakan efek pleotropik dari statin. Penggunaan statin dapat memperbaiki kondisi pasien dengan memperbaki fungsi endotel melalui penambahan produksi oksida nitrit dan antioksidan serta efek antikoagulan. Melalui mekanisme inilah peningkatan Statin dapat memperbaiki kondisi klinis pasien stroke (8).

Selain efek yang disebutkan di atas ternyata terdapat efek statin yang lain, dimana statin juga memiliki efek immune modulatory yang dapat memperbaiki kualitas hidup pasien setelah stroke iskemik akut (9). Mengkonsumsi Atorvastatin 1 hari setelah serangan stroke iskemik ternyata dapat meningkatkan kondisi pasien pada hari ke14, hal ini karena statin dapat mempengaruhi angio-genesis, neurogenesis dan sinaptogenesis dengan menginduksi peningkatan faktor endotel pembu-luh darah (8)

SPARCL menemukan hasil bahwa Atorvastatin dosis tinggi mampu mencegah terjadinya stroke iskemik berulang, akan tetapi dalam penelitian ini masih belum bisa dibuktikan efek neuroprotektif dari statin. Biffi juga melakukan penelitian casecontrol dan meta-analysis pengaruh pemberian statin terhadap perbaikan klinis pasien stroke iskemik akut (10). Penelitian ini menyebutkan bahwa statin memberikan hasil yang bermakna dalam memperbaiki kondisi klinik pasien hanya terjadi pada subtype small vessel ischemic stroke dibanding dengan stroke iskemik subtype lain (10). 
Dari penelitian-penelitian tersebut di atas terbukti bahwa penggunaan statin dibutuhkan untuk mencegah kejadian stroke berulang, akan tetapi berdasarkan pengamatan di lapangan bahwa pasien stroke ada yang diberikan Atorvastatin, dan beberapa pasien lainnya tidak menggunakan Atorvastatin. Oleh sebab itu, maka peneliti tertarik untuk melakukan analisis efektivitas penggunaan obat Atorvastatin pada pasien stroke stroke iskemik di RSUP. Wahidin Sudirohusodo pada tahun 2018.

\section{METODE PENELITIAN}

\section{Rancangan Penelitian}

Jenis penelitian ini adalah Non experiment purposive sampling dengan menggunakan pre-test and post-test design with control group (Polit \& Hungler, 2003). Kelompok kontrol mendapatkan terapi sesuai institusi. Kelompok intervensi mendapatkan terapi tambahan obat atorvastatin.

\section{Lokasi dan Waktu Penelitian}

Waktu penelitian dilaksanakan pada periode bulan 1 Maret1 Mei 2018 dan lokasi penelitian di RSUP Dr. Wahidin Sudirohusodo Makassar.

\section{Bahan Penelitian}

Bahan yang digunakan adalah data rekam medik pasien lengkap (data laboratorium kolestrol total, HDL, LDL, gcs) dan skala mRS (modified Rankin Scale).

\section{Prosedur Kerja}

\section{Penetapan Sampel yang Akan Digunakan}

Kriteria inklusi adalah pasien stroke iskemik yang dirawat periode November 2017-januari 2018, yang mendapatkan terapi atorvastatin, pasien yang tidak mendapatkan atorvastatin (kelompok control), pasien yang memiliki data laboratorium kolestrol total, HDL, LDL yang diperiksa minimal 2 kali, pasien stroke iskemik yang memiliki hasil pemeriksaan kondisi klinis. Kriteria ekslusi adalah pasien stroke yang tidak diperiksa data kolestrolnya, pasien stroke yang mengkonsumsi obat penurun kolestrol yang lain, dan pasien stroke yang meninggal.

\section{Penetapan Obat yang Akan Dievaluasi}

Obat yang akan dievaluasi adalah obat golongan yaitu Atorvastatin yang diresepkan kepada pasien stroke iskemik yang dirawat di RSUP Wahidin Sudirohusodo periode November 2017- Januari 2018.

\section{Pengambilan Data}

Pengambilan data umum dilakukan dengan menggunakan hasil pemeriksaan fisik maupun klinik pasien yang berobat di RSUP Dr. Wahidin Sudirohusodo Makassar. Data pasien meliputi usia, jenis kelamin, riwayat penyakit atau penyakit penyerta, data-data pengobatan, data laboratorium (kolestrol total, LDL, HDL), dan data perbaikan klinis pasien berupa mRS (modified rankin scale) dan penilaian tingkat kesadaran pasien gcs (glasglow coma scale). Data untuk menaganalisis efektivitas dari obat atorvastatin diambil dari hasil pemantauan kondisi pasien pasca mengkonsumsi obat, dengan melihat kondisi umum pasien, nilai data laboratorium dari nilai kolestrol total, LDL, HDL, dan perubahan kondisi klinik pasien yang diukur dengan mRS (modified rankin scale). Data laboratorium pasien diambil dari pemeriksaan darah pasien untuk mengukur kadar kolestrol total, LDL, dan HDL pasien dan akan dibandingkankan hasilnya sebelum dan sesudah menerima terapi atorvastatin, serta melihat perbaikan kondisi klinis pasien yang diukur dengan mRS (modified rankin scale).

\section{Anlisis dan Penyajian Data}

Analisis data dalam penelitian ini dilakukan dengan cara analisis deskriptif dari data hasil penelitian mengenai karakteristik subyek disajikan dalam bentuk narasi dan tabel tabel. Data yang diperoleh dilakukan analisis dengan pengolahan data secara statistik menggunakan paired t-test untuk mengetahui perubahan parameter meliputi kadar kolestrol total, HDL, LDL, dan perbaikan klinis yang diukur dengan mRS sebelum dan sesudah terapi.

\section{HASIL DAN PEMBAHASAN}

Karakteristik pasien yang dijadikan sampel dalam penelitian ini dilihat berdasarkan umur, pasien dengan umur $<55$ tahun berjumlah 9 orang, dan yang berumur 55-65 tahun berjumlah 21 orang, hal ini terjadi karena stroke lebih sering terkena pada pasien pada umur $>55$ tahun, hal ini sesuai dengan hasil penelitian yang dilakukan oleh lestari (2010) bahwa persentasi umur $>55$ tahun lebih banyak menderita stroke dibandingkan dengan umur 40-55 tahun, peningkatan frekuensi stroke seiring dengan peningkatan umur berhubungan dengan proses penuaan, dimana semua organ tubuh mengalami kemunduran fungsi termasuk pembuluh darah otak. Pembuluh darah menjadi tidak elastis terutama bagian endotel yang mengalami penebalan pada bagian intima, sehingga mengakibatkan lumen pembuluh darah semakin sempit dan berdampak pada penurunan aliran darah otak (11). Sedangkan berdasarkan jenis kelamin pada kelompok pasien laki-laki berjumlah 20 orang lebih banyak dibandingkan dengan pasien perempuan yang berjumlah 10 orang, hal ini sesuai dengan penelitian yang dilakukan oleh Puspita dan Putro yang menyatakan bahwa jenis kelamin mempunyai hubungan yang bermakna dengan risiko kejadian stroke dengan risiko pada jenis kelamin laki-laki sebesar 4,375 kali dibandingkan kejadian stroke pada pasien perempuan (12). Dan hal ini sesuai juga dengan hasil penelitian Satu Mustanoja, MD et al dalam jurnal American Heart Assosiation pada tahun 2010 dan ini didukung dengan hasil riset kesehatan dasar Indonesia tahun 2007 yang menyatakan kalau jenis kelamin laki-laki lebih berisiko terkena stroke dibanding perempuan. Hal ini dimungkinkan karena buruknya pola hidup seperti merokok $(4,13)$

\begin{tabular}{|c|c|c|c|}
\hline \multirow{2}{*}{ Karakteristik } & \multirow{2}{*}{ Kategori } & \multicolumn{2}{|c|}{$\mathbf{n}=\mathbf{3 0}$} \\
\hline & & Jumlah & (\%) \\
\hline \multirow{2}{*}{$\begin{array}{c}\text { Kelompok } \\
\text { usia }\end{array}$} & $<55$ tahun & 9 & 30 \\
\hline & 55-65 tahun & 21 & 70 \\
\hline \multirow{2}{*}{ Jenis kelamin } & Laki-laki & 20 & 66.7 \\
\hline & Perempuan & 10 & 33.3 \\
\hline \multirow{9}{*}{$\begin{array}{l}\text { Penyakit } \\
\text { penyerta }\end{array}$} & Hipertensi & & \multirow{3}{*}{$\begin{array}{l}66.7 \\
33.3\end{array}$} \\
\hline & Ya & 20 & \\
\hline & Tidak & 10 & \\
\hline & \multicolumn{3}{|l|}{ Diabetes Melitus } \\
\hline & Ya & 4 & 13.3 \\
\hline & Tidak & 26 & 86.7 \\
\hline & Gangguan jantung & & \\
\hline & $\mathrm{Ya}$ & 5 & 16.7 \\
\hline & Tidak & 25 & 83.3 \\
\hline
\end{tabular}

Selanjuntnya untuk karakteristik penyakit penyerta yang paling banyak persentasinya adalah hipertensi, kejadian hipertensi pada pasien stroke terjadi karena adanya sumbatan pada pembuluh darah menuju sehingga tubuh merespon dengan memberikab kompensasi dengan meningkatan kerja jantung sehingga tekanan darah pasien akan meningkat, hal ini diperlukan untuk meningkatkan perfusi ke otak agar tidak terjadi infark cerebral yang parah setelah terjadinya serangan stroke (14). 


\begin{tabular}{|c|c|c|c|c|}
\hline \multirow[b]{2}{*}{ Golongan obat } & \multirow[b]{2}{*}{ Jenis obat } & \multicolumn{2}{|c|}{ Jumlah } & \multirow{2}{*}{$\begin{array}{c}\text { Total } \\
\mathrm{n}=\mathbf{3 0}(\%)\end{array}$} \\
\hline & & $\begin{array}{l}\text { Kelompok atorvastatin } \\
n=15(\%)\end{array}$ & $\begin{array}{l}\text { Kelompok tanpa atorvastatin } \\
\qquad n=15(\%)\end{array}$ & \\
\hline \multirow{2}{*}{ Anti platelet } & Aspilet & $8(53,0 \%)$ & $8(53,0 \%)$ & $16(53,0 \%)$ \\
\hline & Clopidogrel & $7(47,0 \%)$ & $7(47,0 \%)$ & $14(47,0 \%)$ \\
\hline \multirow{10}{*}{ Antihipertensi } & Ramipril & $2(13,3 \%)$ & $0(0,0 \%)$ & $2(13,3 \%)$ \\
\hline & Concor & $1(6,7 \%)$ & $0(0,0 \%)$ & $1(6,7 \%)$ \\
\hline & Valsartan & $2(13,3 \%)$ & $1(6,7 \%)$ & $3(20,0 \%)$ \\
\hline & Amlodipin & $3(20,0 \%)$ & $5(33,3 \%)$ & $8(26,7 \%)$ \\
\hline & $\mathrm{HCT}$ & $1(6,7 \%)$ & $0(0,0 \%)$ & $1(6,7 \%)$ \\
\hline & Perdipin & $1(6,7 \%)$ & $0(0,0 \%)$ & $1(6,7 \%)$ \\
\hline & Irbesartan & $1(6,7 \%)$ & $0(0,0 \%)$ & $1(6,7 \%)$ \\
\hline & Candesartan & $1(6,7 \%)$ & $1(6.7 \%)$ & $2(6,6 \%)$ \\
\hline & Bisoprolol & $0(0,0 \%)$ & $2(6.6 \%)$ & $2(6,6 \%)$ \\
\hline & Furosemid & $1(6.7 \%)$ & $0(0,0 \%)$ & $2(6,6 \%)$ \\
\hline \multirow{6}{*}{$\begin{array}{l}\text { Perlindungan CNS } \\
\text { (Central nervous } \\
\text { system) }\end{array}$} & Citikolin & $5(33,3 \%)$ & $5(33,3 \%)$ & $10(33,3 \%)$ \\
\hline & Sohobion & $2(13,3 \%)$ & $1(6,7 \%)$ & $3(20,0 \%)$ \\
\hline & Mecobalamin & $4(26,7 \%)$ & $4(26,7 \%)$ & $8(26,7 \%)$ \\
\hline & Neurodex & $3(20,0 \%)$ & $3(20,0 \%)$ & $6(20,0 \%)$ \\
\hline & Asam folat & $1(6,7 \%)$ & $1(6,7 \%)$ & $2(13,3 \%)$ \\
\hline & Neurobion & $0(0,0 \%)$ & $1(6,7 \%)$ & $1(6,7 \%)$ \\
\hline \multirow{4}{*}{ Suplemen } & Vit A & $3(20,0 \%)$ & $2(13,3 \%)$ & $5(33,3 \%)$ \\
\hline & Vit C & $4(26,7 \%)$ & $4(26,7 \%)$ & $8(26,7 \%)$ \\
\hline & Curcuma & $4(26,7 \%)$ & $1(6,7 \%)$ & $5(33,3 \%)$ \\
\hline & B comp & $1(6,7 \%)$ & $2(13,3 \%)$ & $3(20,0 \%)$ \\
\hline \multirow{5}{*}{$\begin{array}{l}\text { Obat gangguan } \\
\text { pencernaan }\end{array}$} & Dulcolax & $1(6,7 \%)$ & $4(26,7 \%)$ & $5(33,3 \%)$ \\
\hline & Omeprazole & $1(6,7 \%)$ & $4(26,7 \%)$ & $5(33,3 \%)$ \\
\hline & Laksadin & $0(0,0 \%)$ & $1(6,7 \%)$ & $1(6,7 \%)$ \\
\hline & Ranitidin & $6(0,9 \%)$ & $5(33,3 \%)$ & $11(36,7 \%)$ \\
\hline & Lanzoprazole & $0(0,0 \%)$ & $1(6,7 \%)$ & $1(6,7 \%)$ \\
\hline
\end{tabular}

Penggunaan obat lain yang paling mendominasi dalam penelitian ini adalah terapi antiplatelet, antihipertensi, neuroprotektan, suplemen, dan obat gangguan pencernaan. Untuk antiplatelet digunakan untuk mencegah terjadinya agregasi platelet (mencegah terjadinya thrombus) obat yang digunakan yaitu aspilet dan clopidogrel, selanjutnya adalah obar antihipertensi digunakan adalah golongan CCB (calcium chanel bloker) yaitu amlodipine dengan dosis $5 \mathrm{mg}$ dan 10 $\mathrm{mg}$, dalam penelitian ini tidak semua pasien diberikan terapi antihipertensi sedangkan berdasarkan tatalaksana terapi diperlukan terapi antihipertensi untuk mencegah terjadinya stroke berulang dan meningkatkan kondisi klinis pasien, walaupun tekanan darah yang tinggi pada pasien stroke harus dipertahankan selama 3 hari, kemudian pengobatan selanjutnya yang digunakan adalah pemberian neuroprotektan Citikolin, neuroprotektan bukan merupakan tatalaksana terapi yang disarankan oleh AHA, meskipun demikian pemberian terapi ini sangat menjadi favorite di Rumah Sakit, selanjutnya untuk pengobatan yang dominan digunakan adalah pemberian suplemen Vitamin C, vitamin $C$ berdasarkan penelitian yang dilakukan dinyatakan bahwa dapat memperbaiki kondisi vascular 25-40 \%, dan menurunkan resiko terjadinya stroke berulang $(2,15)$. Dan terakhir adalah penggunaan obat gangguan pencernaan, obat yang digunakan dalam penelitian ini adalah obat Ranitidin, digunakan untuk mencegah terjadinya efek samping dari penggunaan obat antiplatelet yang dapat menyebabkan terjadinya gangguan lambung (16).

Pada penelitian ini sampel berjumlah 30 orang yang dibagi menjadi 2 kelompok yaitu pasien yang menggunakan atorvastatin dan tidak menggunakan atorvastatin, kelompok pasien yang menggunakan terapi atorvastatin dengan dosis $20 \mathrm{mg} 1 \mathrm{x} 1$, dan rata-rata pemberiannya diberikan pada malam hari yaitu pada pukul 17.00-23.00, sebelum dan sesudah pasien diberikan terapi pasien atorvastatin dilakukan pemeriksaan nilai lipid yaitu kolestrol total, HDL, dan LDL, serta pemeriksaan perbaikan klinis denan meng- gunakan $m R S$ (modified rankin scale) dan gcs (glasglow coma scale), kemudian dilakukan analisis data.

Hasil olah menunjukkan bahwa terjadi penurunan kadar kolestrol total sebesar $25 \%$ dengan nilai rata-rata kolestrol sebelum terapi adalah $194,80 \mathrm{mg} / \mathrm{dl}$ dan turun setelah mendapatkan terapi menjadi $151,40 \mathrm{mg} / \mathrm{dl}$, rata-rata penurunannya adalah $43,4 \mathrm{mg} / \mathrm{dl}$, sedangkan untuk nilai HDL rata-rata nilai sebelum terapi adalah $31,00 \mathrm{mg} / \mathrm{dl}$ dan setelah terapi turun menjadi $27,00 \mathrm{mg} / \mathrm{dl}$, penurunannya adalah 4 $\mathrm{mg} / \mathrm{dl}$. Selanjutnya untuk nilai LDL terjadi penurunan dari 113,80 menjadi $93,20 \mathrm{mg} / \mathrm{dl}$. Hal ini berarti atorvastatin kurang efektif menurunkan kadar lipid, hal ini terjadi karena adanya interaksi yang mungkin terjadi antara atorvastatin dengan amlodipine, dimana dalam penelitian ini atorvastatin dapat amlodipine diberikan bersamaan, amlodipine dan atorvastatin merupakan obat yang dimetabolisme dengan enzim yang sama yaitu sitokrom P450 CYP3A4. Dimana jika diberikan bersamaan maka kemungkinan besar akan terjadi interaksi. Selanjutnya pada penelitian waktu pemberian atorvastatin pada pasien yaitu setelah makan pada malam hari, sedangkan berdasarkan teori profil farmakokinetik atorvastatin, terjadi penurunan penyerapan (absorbs) atorvastatin dengan adanya makanan dalam lambung yaitu sekitar 9-25\% (18).

\begin{tabular}{|c|c|c|c|c|}
\hline \multirow[b]{2}{*}{ Variabel } & \multicolumn{2}{|c|}{$\begin{array}{c}\text { Kelompok Atorvastatin } \\
(n=5)\end{array}$} & \multicolumn{2}{|c|}{ Keterangan } \\
\hline & $\begin{array}{l}\text { Sebelum terapi } \\
(\mathrm{mg} / \mathrm{dl})\end{array}$ & $\begin{array}{c}\text { Sesudah } \\
\text { terapi } \\
\text { (mg/dl) }\end{array}$ & $\begin{array}{l}\text { Selisih } \\
\text { (mg/dl) }\end{array}$ & Perubahan \\
\hline $\begin{array}{l}\text { Kolestrol } \\
\text { total }\end{array}$ & $194,80 \pm 53,81$ & $\begin{array}{c}151.40 \pm \\
36,78\end{array}$ & $-43,4$ & Penurunan \\
\hline $\mathrm{HDL}$ & $31,00 \pm 2,55$ & $27.00 \pm 2,12$ & $-4,0$ & Penurunan \\
\hline LDL & $113,80 \pm 50,85$ & $93.20 \pm 32,54$ & $-20,6$ & penurunan \\
\hline
\end{tabular}


Tabel 4. Nilai Kolesterol Pada Kelompok yang Tidak Mendapatkan Terapi Atrovastatin

\begin{tabular}{|c|c|c|c|c|}
\hline \multirow[b]{2}{*}{ Variabel } & \multicolumn{2}{|c|}{$\begin{array}{c}\text { Kelompok Atorvastatin } \\
(n=5)\end{array}$} & \multicolumn{2}{|c|}{ Keterangan } \\
\hline & $\begin{array}{c}\text { Sebelum } \\
\text { terapi } \\
(\mathrm{mg} / \mathrm{dl})\end{array}$ & $\begin{array}{c}\text { Sesudah } \\
\text { terapi } \\
(\mathrm{mg} / \mathrm{dl})\end{array}$ & $\begin{array}{l}\text { Selisih } \\
\text { (mg/dl) }\end{array}$ & Perubahan \\
\hline $\begin{array}{l}\text { Kolestrol } \\
\text { total }\end{array}$ & $182,60 \pm 20,34$ & $184,60 \pm 16,43$ & 2,0 & Peningkatan \\
\hline $\mathrm{HDL}$ & $51.20 \pm 9,04$ & $59,20 \pm 17,34$ & 12,2 & Peningkatan \\
\hline LDL & $129,00 \pm 26,86$ & $131,00 \pm 25,12$ & 2,0 & Peningkatan \\
\hline
\end{tabular}

Dan selanjutnya untuk nilai perbaikan klinis bahwa kelompok pasien yang menggunakan Atorvastatin pada saat sebelum terapi nilai $m R S$ dengan kategori baik terbanyak adalah pasien dengan nilai $m R S 3$ dengan persentasi $26.7 \%$ kemudian nilai $m R S 2$ dengan persentasi $13.3 \%$, sedangkan pada saat setelah terapi atorvastatin terjadi peningkatan kondisi klinis dengan nilai $m R S 3$ menurun dari 4 orang pasien menjadi 2 orang pasien saja, kemudian untuk nilai $m R S 2$ meningkat dari 2 orang pasien menjadi 7 orang pasien, sedangkan untuk nilai mRS 0 juga meningkat frekuensinya 0 menjadi 4 orang pasien. Sedangkan untuk kondisi klinik buruk dengan nilai $m R S$ 4-6 dari tabel 4.11 terlihat nilai mRS 4 pada saat sebelum terapi dengan frekuensi 6 orang persentasi $40 \%$, kemudian nilai $m R S 5$ frekuensinya 3 orang persentasi $20 \%$, kemudian setelah terapi terjadi penurunan jumlah pasien yang mengalami kondisi buruk artinya pasienpasien yang mengalami kondisi klinik buruk pada saat sebelum terapi atorvastatin menjadi lebih baik setelah mendapatkan terapi atorvastatin, setelah mendapatkan terapi atorvastatin pasien dengan nilai $m R S 4$ menurun frekuensinya menjadi 2 orang, terjadi penurunan menjadi $26,7 \%$, kemudian nilai $m R S 5$ juga menurun sebanyak $100 \%$ Selanjutnya untuk pasien yang tidak menggunakan atorvastatin, untuk kondisi klinis baik (nilai $m R S 0-3$ ) pada saat awal pemeriksaan untuk nilai $m R S 1$ dan 2 frekuensinya sama yaitu 2 dengan persentasi 13,3\%, kemudian untuk nilai $m R S 3$ frekuensinya adalah 1 dengan persentasi $6,7 \%$, dan setelah dirawat dan mendapatkan terapi (bukan atorvastatin) pasien-pasien mengalami peningkatan kondisi klinik, dengan mRS 1 frekuensinya menjadi 3 persentasi $20 \%$, sedangkan untuk $m R S 2$ meningkat frekuensinya menjadi 3 dengan persentasi $20 \%$, dan untuk nilai $m R S 3$ terjadi penurunan dengan frekuensi pada saat rawat inap 1 dan pada saat rawat jalan menjadi 0 . Selanjutnya untuk kondisi klinik buruk $(m R S>3)$ terlihat untuk nilai $m R S 4$ frekuensinya 4 persentasi $26,7 \%$ pada saat sebelum terapi (awal masuk rumah sakit), kemudian selanjutnya setelah terapi (bukan atorvastatin) frekuensinya menurun menjadi 1 orang dengan persentasi $6,7 \%$, selanjutnya untuk nilai $m R S 5$ pada saat sebelum terapi (awal masuk rumah sakit) frekuensinya adalah 6 orang kemudian meningkat frekuensinya menjadi 8 orang, terjadinya peningkatan pasien yang mengalami kondisi klinis buruk dengan nilai $m R S$ yaitu sebanyak sekitar $13,3 \%$. Setelah dilakukan pengolahan data dengan menggunakan uji $T$, didapatkan perbedaan hasil untuk variabel $m R S$ terdapat perbaikan klinis pasien yang mendapatkan atorvastatin dengan nilai signifikannya $p=0,001$ hasil ini sangat berbeda nyata dari hasil kelompok pasien tanpa Atorvastatin nilai $p=0,610$. Hal ini sejalan dengan penelitian yang dilakukan oleh Alexander dkk pada tahun 2010 yang menyatakan bahwa pasien stroke iskemik yang mendapatkan Atorvastatin pada saat rawat inap di rumah sakit dapat memperbaiki kondisi klinik pasien, hal ini tentu juga didukung dengan penggunaan obat-obat lainnya terutama pengobatan utama yang diberikan kepada pasien seperti diberikan antiplatelet, antihipertensi dan neuroprotektan (19). Dan hal ini juga di dukung oleh penelitian yang dilakukan oleh Yoon dkk yang menyatakan bahwa proporsi pasien yang menggunakan statin ketika pertama kali masuk rumah sakit dengan stroke sangat meningkat dengan cepat. Dan penggunaan statin sebagai pretreatment mempunyai hubungan yang bermakna dengan peningkatan perbaikan klinis ketika pasien keluar dari rumah sakit $(20,21)$. Hal ini mendukung penggunaan statin dengan segera sebagai terapi pada pasien-pasien setelah stroke dengan ratarata lama masa perawatan 5 hari . Dan yang paling mendukung keberhasilan perbaikan klinis pasien dalam penelitian ini adalah adanya pemberian obat lain seperti antiplatelet, antihipertensi yang merupakan pengobatan utama pada pasien stroke iskemik.

\begin{tabular}{|c|c|c|c|c|c|c|c|c|}
\hline \multirow{3}{*}{$\begin{array}{l}\text { Nilai } \\
\text { mRS }\end{array}$} & \multicolumn{4}{|c|}{$\begin{array}{l}\text { Kelompok Atorvastatin } \\
\qquad n=15\end{array}$} & \multicolumn{4}{|c|}{$\begin{array}{c}\text { Kelompok tanpa } \\
\text { Atorvastatin } \\
n=15\end{array}$} \\
\hline & \multicolumn{2}{|c|}{$\begin{array}{l}\text { Sebelum } \\
\text { terapi }\end{array}$} & \multicolumn{2}{|c|}{$\begin{array}{c}\text { Setelah } \\
\text { terapi }\end{array}$} & \multicolumn{2}{|c|}{$\begin{array}{l}\text { Sebelum } \\
\text { terapi }\end{array}$} & \multicolumn{2}{|c|}{$\begin{array}{c}\text { Setelah } \\
\text { terapi }\end{array}$} \\
\hline & f & $\begin{array}{c}\text { Persen } \\
(\%)\end{array}$ & f & $\begin{array}{c}\text { Persen } \\
(\%)\end{array}$ & $f$ & $\begin{array}{c}\text { Persen } \\
(\%)\end{array}$ & f & $\begin{array}{c}\text { Persen } \\
(\%)\end{array}$ \\
\hline 1 & 0 & 0,0 & 4 & 26,7 & 2 & 13,3 & 3 & 20,0 \\
\hline 2 & 2 & 13,3 & 7 & 46,7 & 2 & 13,3 & 3 & 20,0 \\
\hline 3 & 4 & 26,7 & 2 & 13,3 & 1 & 6,7 & 0 & 0,0 \\
\hline 4 & 6 & 40,0 & 2 & 13,3 & 4 & 26,7 & 1 & 6,7 \\
\hline 5 & 3 & 20,0 & 0 & 0,0 & 6 & 40,0 & 8 & 53,3 \\
\hline \multicolumn{9}{|c|}{$\begin{array}{l}\text { Catatan: } \\
\text { mRS =0-3 (baik), >3 (Buruk); Signifikan jika nilai } p<0.05\end{array}$} \\
\hline \multicolumn{4}{|c|}{ Kelompok Atorvastatin } & \multicolumn{5}{|c|}{ Kelompok Tanpa Atorvastatin } \\
\hline \multicolumn{2}{|c|}{ Mean $\pm S D$} & & Sig & \multicolumn{3}{|c|}{ Mean \pm SD } & & Sig \\
\hline \multicolumn{3}{|c|}{$1,533 \pm 1,356$} & 001 & \multicolumn{3}{|c|}{$0,133 \pm 0,990$} & & 0,610 \\
\hline
\end{tabular}

\section{KESIMPULAN}

Atorvastatin efektif menurunkan kadar kolestrol total sebesar $25 \%$, tetapi atorvastatin tidak efektif meningkatkan kadar HDL, dan pada nilai LDL atorvastatin efektif menurunkan kadar kolestrol LDL sekitar 20\%. Sedangkan pada perbaikan nilai klinis yang diukur dengan mRS kelompok yang menggunakan atorvastatin lebih baik nilai mRS nya dibandingkan kelompok yang tidak menggunakan atorvastatin, ini berarti ada hubungan yang signifikan antara pemberian terapi atorvastatin terhadap perbaikan nilai klinis pasien.

\section{UCAPAN TERIMA KASIH}

Penulis mengucapkan terima kasih kepada LPDP Indonesia atas bantuan pendanaan. Penulis juga berterima kasih kepada Fakultas Farmasi Universitas Hasanuddin atas dukungan moril dan sarana selama penulis melakukan penelitian.

\section{DAFTAR PUSTAKA}

1. Ennen KA, 2004. Knowledge of stroke warning symptoms and risk factors: variations by rural and urban categorie. Thesis. Chicago. University of Illinois.

2. American Heart Association/American Stroke Association (AHA/ASA) 2014. Heart disease and stroke statistics-2012 Update. Diakses dari:http://circ.ahajournals.org/content/125/1/e2.

3. Stroke Forum, 2015. Epidemiology of stroke. Diakses tanggal 26 Januari 2015dari:http://www.strokeforum.com/strokebackground/epidemiolo gy.html

4. World Health Organization, 2010. The atlas of heart disease and stroke.Diakses:dariwww.who.int/cardiovascular_diseases/resources/at las/en/ tanggal 22 Januari 2015.

5. Misbach, Jusuf, 2010. Diagnostic aspect, pathophysiology, management Journal of Stroke; 1(1), hal: 46-54. 
6. Yastroki, 2009. Indonesia tempati urutan pertama didunia dalam jumlah terbanyak penderita stroke. Diakses tanggal 20 Januari 2015 dari: http://www.yastroki.or.id/read.php?id=341

7. Adult Treatment Panel-ATP-III. 2001. The Third Report of the Detection Evaluation, and Treatment of High Blood Cholesterol in Adult. National Cholesterol Education Program (NCEP).

8. Moonis, M., Kane, K., Schwiderski, U., Sandage, B.W., Fisher, M.. 2005 'HMG-CoA Reductase Inhibitors Improve Acute Ischemic Stroke Outcome', Stroke, 36:1298-1300.

9. Yoon SS et al. 2004. Rising statin use and effect on ischemic stroke outcome. BMC Medicine; 2:4

10. Biffi A., Greenberg S.M. 2011. Cerebral Amyloid Angiopathy: A Systematic Review. J Clin Neurol. 7: 1-9

11. Kristiyawati, S.P., Irawaty, D., Hariyati, Rr.T.S. 2009. "Faktor Risiko yan Berhubungan de-ngan Kejadian Stroke di RS Panti Wilasa Citarum Semarang", Jurnal Keperawatan dan Kebidanan (JIKK),Volume 1 (1)

12. Puspita, M dan Putro, G. 2008. "Hubungan Gaya Hidup terhadap Kejadian Stroke di Rumah Sakit Umum daerah Gambiran Kediri", Buletin Penelitian Sistem Kesehatan, Volume 11 (3), hal 263-269.

13. Mustanoja, Satu. MD, PhD, AtteMeretoja, MD, MSc, JukkaPutaala, MD PhD. Et al. 2010.American Heart Assosiation .Finland :Department of Neurology.
14. Stroke Association. High blood pressure and stroke. http://www.stroke.org.uk/sites/default/files/files/F06_High\%20blood \%20 pressure\%20and\%20stroke.pdf. Accessed on Feb 23, 2015

15. Phyo K. Myint et al, 2011, American Journal Nutrition:Cambridge University.

16. Koda-Kimble, Mary Anne et al. 2009. Applied therapeutics : the clinical use of drugs. Lippincott Williams \& Wilkins. Philadelphia, Pennsylvania : USA.

17. Branko N Huisa, Andrew B Stemer ,Justin A Zivin, 2010, Journal Vascular Health and Risk Management.

18. Baxter, Karen. 2010. Stockley's Drug Interactions. A source book of interactions, their mechanisms, clinical importance and management, Ninth edition.Pharmaceutical Press. USA.

19. Alexander DJ. 2000. Newcastle Disease and other Avian Paramyxovirus. Rev. sci. tech. Off. int. Epiz. Vol. 19, No. 2, Hal. 443-462. Central Veterinary Laboratory, Weybridge, New Haw, Addlestone, Surrey KT15 3NB, United Kingdom

20. Yoon SS et al. 2004. Rising statin use and effect on ischemic stroke outcome. BMC Medicine; 2:4

21. Reeves, M..J, Gargano, J.W., Luo, Z., Mullard, A.J., Jacobs, B.S., Majid, A., dkk. 2008, 'National Acute Stroke Registry Michigan Prototype Investigators: Effect of pretreatment with statins on ischemic stroke outcomes', Stroke, 39:1779-85. 